\title{
Erratum to: Gold nanoparticles assisted characterization of amine functionalized polystyrene multiwell plate and glass slide surfaces
}

\author{
Gunasekaran Dharanivasan - Thangavelu Rajamuthuramalingam • \\ Denison Michael Immanuel Jesse • Nagappan Rajendiran • \\ Krishnan Kathiravan
}

Published online: 1 May 2014

(c) The Author(s) 2014. This article is published with open access at Springerlink.com

\section{Erratum to: Appl Nanosci}

DOI 10.1007/s13204-013-0290-1

In the original publication of the article, the subheadings of Table 1 were incorrectly published. The correct version of Table 1 is given below.

The online version of the original article can be found under doi:10.1007/s13204-013-0290-1.

G. Dharanivasan - T. Rajamuthuramalingam .

D. Michael Immanuel Jesse $\cdot$ K. Kathiravan ( $\varangle)$

Department of Biotechnology, University of Madras,

Guindy Campus, Chennai 600 025, Tamil Nadu, India

e-mail: kathir68@rediffmail.com; drkkathiravan@gmail.com

N. Rajendiran

Department of Polymer Science, University of Madras,

Guindy Campus, Chennai 600 025, Tamil Nadu, India 
Table 1 XPS binding energy peaks of amine modified and AuNPs stained PS plate and GS surfaces with their possible assignments

\begin{tabular}{|c|c|c|c|c|c|c|c|}
\hline \multicolumn{8}{|l|}{ Amine functionalized PS plate surface } \\
\hline Elements & $\mathrm{C} 1 \mathrm{~s}$ & & & $\mathrm{~N}$ 1s & $\mathrm{O} 1 \mathrm{~s}$ & Si $2 p$ & \\
\hline Binding energy $(\mathrm{eV})$ & 285.2 & 286.5 & 288.9 & 400.3 & 532.4 & 103.6 & \\
\hline Types of assignments & $\mathrm{C}-\mathrm{C} / \mathrm{C}-\mathrm{H}$ & $\mathrm{C}-\mathrm{N}$ & $\mathrm{C}-\mathrm{O}$ & $\mathrm{NH}_{3}{ }^{+}$ & $\mathrm{O}-\mathrm{Si}$ & $\mathrm{Si}-\mathrm{O} / \mathrm{Si}-\mathrm{C}$ & \\
\hline Relative atomic concentration $(\%)$ & 73.05 & & & 6.60 & 16.53 & 3.83 & \\
\hline \multicolumn{8}{|c|}{ AuNPs stained amine functionalized PS plate surface } \\
\hline Elements & $\mathrm{C} 1 \mathrm{~s}$ & & & $\mathrm{~N}$ 1s & Si $2 p$ & $\mathrm{Au} 4 \mathrm{f}$ & \\
\hline Binding energy $(\mathrm{eV})$ & 285.1 & 287.1 & 288.7 & 400.5 & 102.8 & 83.8 & 87.4 \\
\hline Types of assignments & $\mathrm{C}-\mathrm{C} / \mathrm{C}-\mathrm{H}$ & $\mathrm{C}-\mathrm{N}$ & $\mathrm{C}-\mathrm{O}$ & $\mathrm{NH}_{2} / \mathrm{NH}_{3}{ }^{+}-\mathrm{C}$ & $\mathrm{Si}-\mathrm{O}$ & $\mathrm{Au} 4 \mathrm{f} 7 / 2$ & $\mathrm{Au} 4 \mathrm{f} 5 / 2$ \\
\hline \multicolumn{8}{|l|}{ Amine functionalized GS surface } \\
\hline Elements & $\mathrm{C} 1 \mathrm{~s}$ & & & $\mathrm{~N}$ 1s & $\mathrm{O} 1 \mathrm{~s}$ & Si $2 p$ & \\
\hline Binding energy $(\mathrm{eV})$ & 284.4 & 285.4 & 287.0 & 400.5 & 532.4 & 103.3 & \\
\hline Types of assignments & $\mathrm{C}-\mathrm{C}$ & $\mathrm{C}-\mathrm{N}$ & $\mathrm{HN}-\mathrm{CO}$ & $\mathrm{NH}_{3}{ }^{+}$ & $\mathrm{O}-\mathrm{Si}$ & $\mathrm{Si}-\mathrm{O}$ & \\
\hline Relative atomic concentration (\%) & 53.67 & & & 1.25 & 24.04 & 21.04 & \\
\hline \multicolumn{8}{|c|}{ AuNPs stained amine functionalized GS surface } \\
\hline Elements & $\mathrm{C} 1 \mathrm{~s}$ & & & $\mathrm{~N}$ 1s & Si $2 p$ & $\mathrm{Au} 4 \mathrm{f}$ & \\
\hline Binding energy $(\mathrm{eV})$ & 283.9 & 285.6 & 288.3 & 400.0 & 102.6 & 84.3 & 88.0 \\
\hline Types of assignments & $\mathrm{C}-\mathrm{C}$ & $\mathrm{C}-\mathrm{N}$ & $\mathrm{HN}-\mathrm{CO}$ & $\mathrm{NH}_{2} / \mathrm{NH}_{3}{ }^{+}$ & $\mathrm{Si}-\mathrm{O}$ & $\mathrm{Au} 4 \mathrm{f} 7 / 2$ & $\mathrm{Au} 4 \mathrm{f} 5 / 2$ \\
\hline
\end{tabular}

Open Access This article is distributed under the terms of the Creative Commons Attribution License which permits any use, distribution, and reproduction in any medium, provided the original author(s) and the source are credited. 